\title{
Monitoring frequency influences the analysis of resting behaviour in a forest carnivore
}

Received: 11 September 2014 / Accepted: 20 February 2015 / Published online: 1 March 2015

(C) The Ecological Society of Japan 2015

\begin{abstract}
Resting sites are key structures for many mammalian species, which can affect reproduction, survival, population density, and even species persistence in human-modified landscapes. As a consequence, an increasing number of studies has estimated patterns of resting site use by mammals, as well as the processes underlying these patterns, though the impact of sampling design on such estimates remain poorly understood. Here we address this issue empirically, based on data from 21 common genets radiotracked during 28 months in Mediterranean forest landscapes. Daily radiotracking data was thinned to simulate every other day and weekly monitoring frequencies, and then used to evaluate the impact of sampling regime on estimates of resting site use. Results showed that lower monitoring frequencies were associated with major underestimates of the average number of resting sites per animal, and of
\end{abstract}

Electronic supplementary material The online version of this article (doi:10.1007/s11284-015-1253-7) contains supplementary material, which is available to authorized users.

F. Carvalho $(\bowtie) \cdot$ R. Carvalho $\cdot$ A. Galantinho $\cdot$ A. Mira Unidade de Biologia da Conservação, Departamento de Biologia, Universidade de Evora, Núcleo da Mitra, 7002-554 Evora, Portugal

E-mail: filipescpcarvalho@gmail.com

Tel.: +351266759350

F. Carvalho $\cdot$ A. Galantinho

FEC-Funcionamento dos Ecossistemas e Conservação, ICAAM-Instituto de Ciências Agrárias e Ambientais Mediterrânicas, Universidade de Evora, Pólo da Mitra, 7002-554 Évora, Portugal

F. Carvalho $\cdot$ R. Carvalho $\cdot$ A. Mira

CIBIO/InBio-UE - Centro de Investigação em Biodiversidade e Recursos Genéticos/InBio Laboratório Associado, Universidade de Évora, Pólo de Évora, Casa do Cordovil $2^{\circ}$ Andar, Rua Dr. Joaquim Henrique da Fonseca, 7000-890 Évora, Portugal

P. Beja

EDP Biodiversity, CIBIO/InBio-Centro de Investigação em Biodiversidade e Recursos Genéticos/InBio Laboratório Associado, Universidade do Porto, Campus Agrário de Vairão, 4485-661 Vairão, Portugal site reuse rates and sharing frequency, though no effect was detected on the percentage use of resting site types. Monitoring frequency also had a major impact on estimates of environmental effects on resting site selection, with decreasing monitoring frequencies resulting in higher model uncertainty and reduced power to identify significant explanatory variables. Our results suggest that variation in monitoring frequency may have had a strong impact on intra- and interspecific differences in resting site use patterns detected in previous studies. Given the errors and uncertainties associated with low monitoring frequencies, we recommend that daily or at least every other day monitoring should be used whenever possible in studies estimating resting site use patterns by mammals.

Keywords Carnivores - Data thinning - Forest ecology $\cdot$ Resting sites $\cdot$ Sampling regime

\section{Introduction}

Resting sites are key structures for many mammalian species, by providing shelter against predators, thermoregulatory stability and secure access to resources (Brown et al. 2014; Carvalho et al. 2014). The spatial distribution of resting sites influences important aspects of mammalian biology, including the use of foraging habitats, reproduction success, social behaviour and population size (Banks et al. 2011; Weir et al. 2012). In recent years it has become apparent that human activities often reduce the availability of adequate resting sites, which in turn can affect the ability of species to persist in human-modified landscapes (Lindenmayer et al. 2012a; Manning et al. 2013). As a consequence, there has been increasing interest in characterising the resting ecology of mammals, in order to identify species most at risk and devising appropriate management solutions (Birks et al. 2005).

A key aspect of mammalian resting ecology is the typology of resting sites used, including for instance tree 